\title{
Catalogue and Atlas of giant aufeis of the North- East of Russia
}

\author{
Vladimir Alexeev ${ }^{1}$, Olga Makarieva ${ }^{1,2 *}$, Andrey Shikhov ${ }^{3}$, Nataliia Nesterova $^{2,4}$, Andrey \\ Ostashov $^{5}$, and Anastasiya Semakina ${ }^{3}$ \\ ${ }^{1}$ Melnikov Permafrost Institute, 677010 Yakutsk, Russia \\ ${ }^{2}$ Saint-Petersburg State University, 199034 Saint-Petersburg, Russia \\ ${ }^{3}$ Perm State University, 614990 Perm, Russia \\ ${ }^{4}$ State Hydrological Institute, 199053 Saint-Petersburg, Russia \\ ${ }^{5}$ Saint Petersburg branch Of the Institute of Geoecology of the Russian Academy of Sciences, 199004 \\ Saint-Petersburg, Russia
}

\begin{abstract}
This study presents the results of development of the Catalogue and Atlas of giant aufeis-taryns in the North-East of Russia. The characteristics of aufeis in the North-East of Russia for the last 70 years have been generalized and systematized into the Catalogue database using data from the Cadastre of aufeis (1958) and Landsat images for the period 2013-2017 for the Yana, Indigirka, Kolyma River basins and Chukotka area. In total the territory more than 1.9 million $\mathrm{km}^{2}$ is covered by the study. The Catalogue contains the information about the location and characteristics of more than 4600 aufeis fields. The release of the Atlas of aufeis-taryns in the North-East of Russia has been announced. It reveals the history of study, origin, distribution, and specific features of aufeis and is supplemented with medium- and large-scale maps of aufeis with their seasonal and long-term dynamics.
\end{abstract}

\section{Introduction}

Aufeis is a peculiar form of seasonal glaciation that is typical for almost the entire permafrost region and consists of large ice masses in river valleys that are formed as a result of layer-by-layer freezing of ground water spilled onto the surface. Aufeis-taryns are especially widespread in the North-East of the Asian continent where they are of gigantic size: the area of aufeis fields is measured in tens of square kilometres, and the ice thickness reaches 10-12 m. Systematic study of aufeis began in the 1930 and currently there is a new wave of research interest to aufeis $[1,2,3,4]$.

The climate warming over the past 50 years has caused the changes of the area and volume of aufeis fields. For example, the volume of the giant Anmangynda aufeis on the Kolyma decreased by half during the period from 1960 to 1995 [1]. In some watersheds, new aufeis has appeared. A complex of particularly dangerous cryogenic phenomena is developing within the aufeis areas of river valleys significantly affecting the economic activities in the region.

\footnotetext{
* Corresponding author: omakarieva@gmail.com
} 
At the same time, despite the relevance of aufeis studies, the genetic nature of giant aufeis formations remains largely unknown. Until now, for example, it is not clear where such a huge amount of water feeding aufeis is taken from among the solid and powerful permafrost, the reasons for the collapse and appearance of new aufeis fields are not known, the migration routes of aufeis-forming waters are mysterious, the mechanism of formation of injection subglacial ice layers, the structure and patterns of development of aufeis landscapes, dangerous permafrost and hydrothermal phenomena caused by aufeis are poorly studied. It is not possible to study aufeis formation without generalizing existing data and obtaining new ones. Therefore, the purpose of the study was to obtain new data and systematize them together with historical data in a uniform database and create the Atlas of the aufeis-taryns of the North-East of Russia.

\section{Aufeis-taryns of the North-East of Russia}

In the North-East of Russia, more than 10 thousand aufeis fields have been identified, covering an area of about 14 thousand $\mathrm{km}^{2}$, about $3.5 \%$ of the total area of the region. The relative aufeis share of some river basins area reaches $12 \%$. The area of the largest Momskaya aufeis exceeds $100 \mathrm{~km}^{2}$. Most aufeis fields are located in the areas with highly dissected terrain, in the areas of foothill sloping plains and in intermountain depressions. Here they form specific high-altitude belts and linear zones, confined to tectonic faults. The lower boundary of the aufeis zones is 50-100 m above the regional base of erosion. The aufeis is supplied by the waters of subsurface, floodplain and lake taliks, which penetrate the thick permafrost and divide it into a system of large blocks of complex configuration. The aufeis accumulates $26 \mathrm{~km}^{3}$ of ground water in the free water exchange zone $(36 \%$ of their total dynamic reserves). The total volume of aufeis is about $30 \mathrm{~km}^{3}$, which corresponds to $25 \mathrm{~mm}$ of water layer at the area of 1.2 million $\mathrm{km}^{2}$ [5]. Aufeis is the climate regulator of underground and river flow. In winter, their formation takes from 70 to $90 \%$ of the winter river flow or $40-80 \%$ of the annual amount of underground flow. In some watersheds of small rivers, the volume of aufeis water may reach $100-150 \mathrm{~mm}$ - which is about the volume of annual runoff. High in the mountains and in the Arctic, up to $50 \%$ of the aufeis fields do not completely melt, i.e. there is an interannual redistribution of water resources. 30-40\% of the aufeis supply is spent on the formation of underground injection ice, which is genetically associated with the development of aufeis processes [5].

\section{Catalogue of aufeis of the North-East of Russia}

The characteristics of aufeis of the North-East of Russia for the last 70 years are summarized in the new Catalogue using data from the Cadastre of aufeis $[6,7]$ and Landsat images for the period 2013-2017 for the basins of the Indigirka [8], Yana, Kolyma rivers and Chukotka area [9] (Fig. 1). In total the territory more than 1.9 million $\mathrm{km}^{2}$ is covered by the study.

The developed Catalogue contains the coordinates and characteristics of 896 aufeis with a total area of $2064 \mathrm{~km}^{2}$ in the Indigirka River basin [3, 10], 385 aufeis with a total area of $738 \mathrm{~km}^{2}$ in the Yana River basin, 1765 aufeis with a total area of $1945 \mathrm{~km}^{2}$ in the Kolyma River basin, and 1599 aufeis with a total area of $2434 \mathrm{~km}^{2}$ in Chukotka (Fig. 2). The Table shows data on the comparison of matching and not matching aufeis of the Cadastre (1958) and the Landsat images within the study area.

The data of Catalogue will be used for the analysis of aufeis dynamic in the last decades, their impact on winter flow, their reaction to warming climate and degrading permafrost in the future. 
Table. Data correlation of aufeis based on the Cadastre (1958) and the Landsat images.

\begin{tabular}{|l|l|l|l|l|}
\hline $\begin{array}{c}\text { Territory (river } \\
\text { basin) }\end{array}$ & Area, $\mathrm{km}^{2}$ & \multicolumn{1}{|c|}{ Data source } & Matching aufeis & Not matching aufeis \\
\hline \multirow{2}{*}{ Yana } & \multirow{2}{*}{238000} & Cadaster $(1958)$ & $68\left(616 \mathrm{~km}^{2}\right)$ & $117\left(122 \mathrm{~km}^{2}\right)$ \\
\cline { 3 - 5 } & & Landsat & $262\left(320 \mathrm{~km}^{2}\right)$ & $321\left(107 \mathrm{~km}^{2}\right)$ \\
\hline \multirow{2}{*}{ Indigirka } & \multirow{2}{*}{360000} & Cadaster $(1958)$ & $634\left(1905 \mathrm{~km}^{2}\right)$ & $262\left(159 \mathrm{~km}^{2}\right)$ \\
\cline { 3 - 5 } & Landsat & $611\left(1037 \mathrm{~km}^{2}\right)$ & $602\left(250 \mathrm{~km}^{2}\right)$ \\
\hline \multirow{2}{*}{ Kolyma } & \multirow{2}{*}{ C43000 } & Cadaster $(1958)$ & $1101\left(1606 \mathrm{~km}^{2}\right)$ & $664\left(339 \mathrm{~km}^{2}\right)$ \\
\cline { 3 - 5 } & & Landsat & $1073\left(714 \mathrm{~km}^{2}\right)$ & $1143\left(165 \mathrm{~km}^{2}\right)$ \\
\hline \multirow{2}{*}{ Chukotka } & \multirow{2}{*}{721500} & Cadaster $(1958)$ & $1001\left(1998 \mathrm{~km}^{2}\right)$ & $598\left(436 \mathrm{~km}^{2}\right)$ \\
\cline { 3 - 5 } & & Landsat & $979\left(750 \mathrm{~km}^{2}\right)$ & $1186\left(218 \mathrm{~km}^{2}\right)$ \\
\hline
\end{tabular}

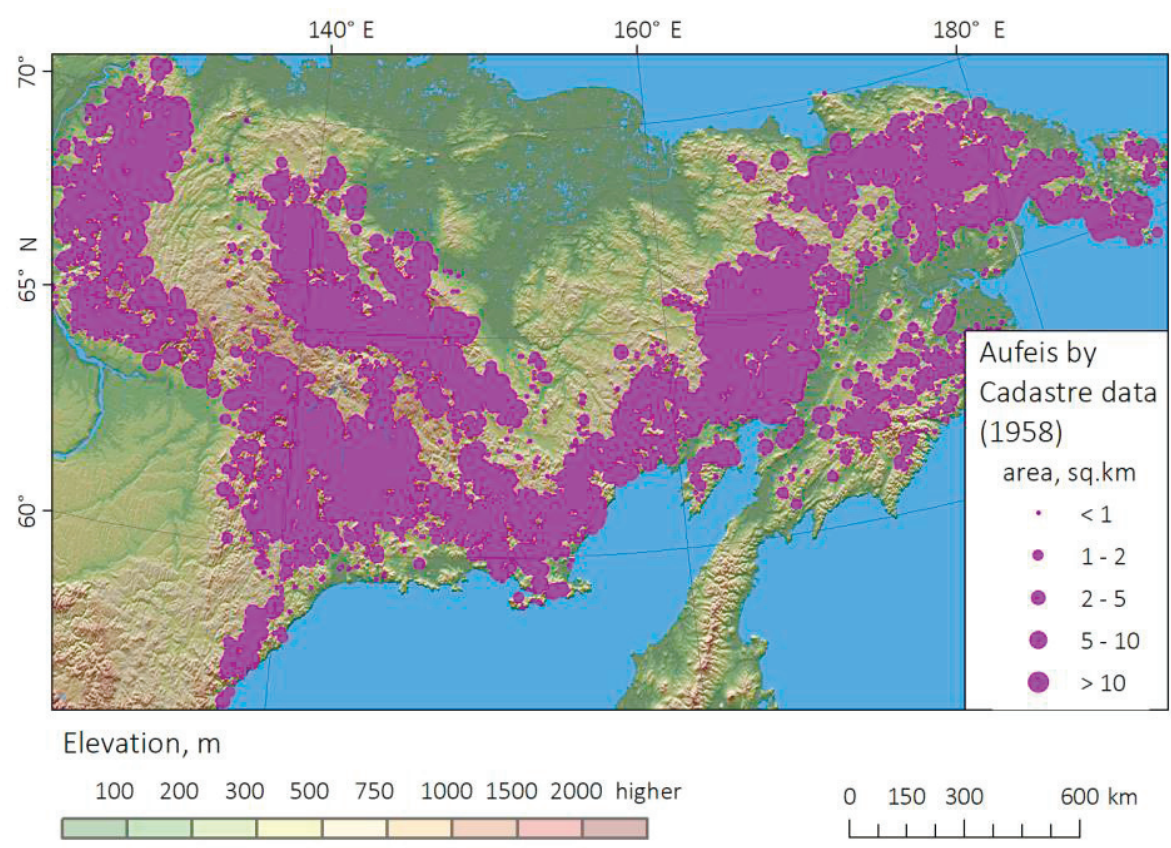

Fig. 1. The aufeis fields of the newly developed Catalogue.

\section{Atlas of giant aufeis of the North-East of Russia}

Based on the aufeis Catalogue, the Atlas of aufeis is being elaborated.

The Atlas consists of two parts. First part (text) reveals the history of the aufeis studies, the origin and specific features of the aufeis. The shape, size, structure, and variability of aufeis fields in time and space are described and illustrated with colour photographs and graphs. The dependence of aufeis dynamic on permafrost-hydrogeological, hydro-climatic, geomorphological, and geotectonic conditions is shown, as well as their impacts on landscapes, terrain and distribution of water, snow-ice, mineral, and biological resources. Special sections are devoted to dangerous permafrost-geological, glacial and hydrological phenomena that affect engineering development of the area and aufeis resources. 


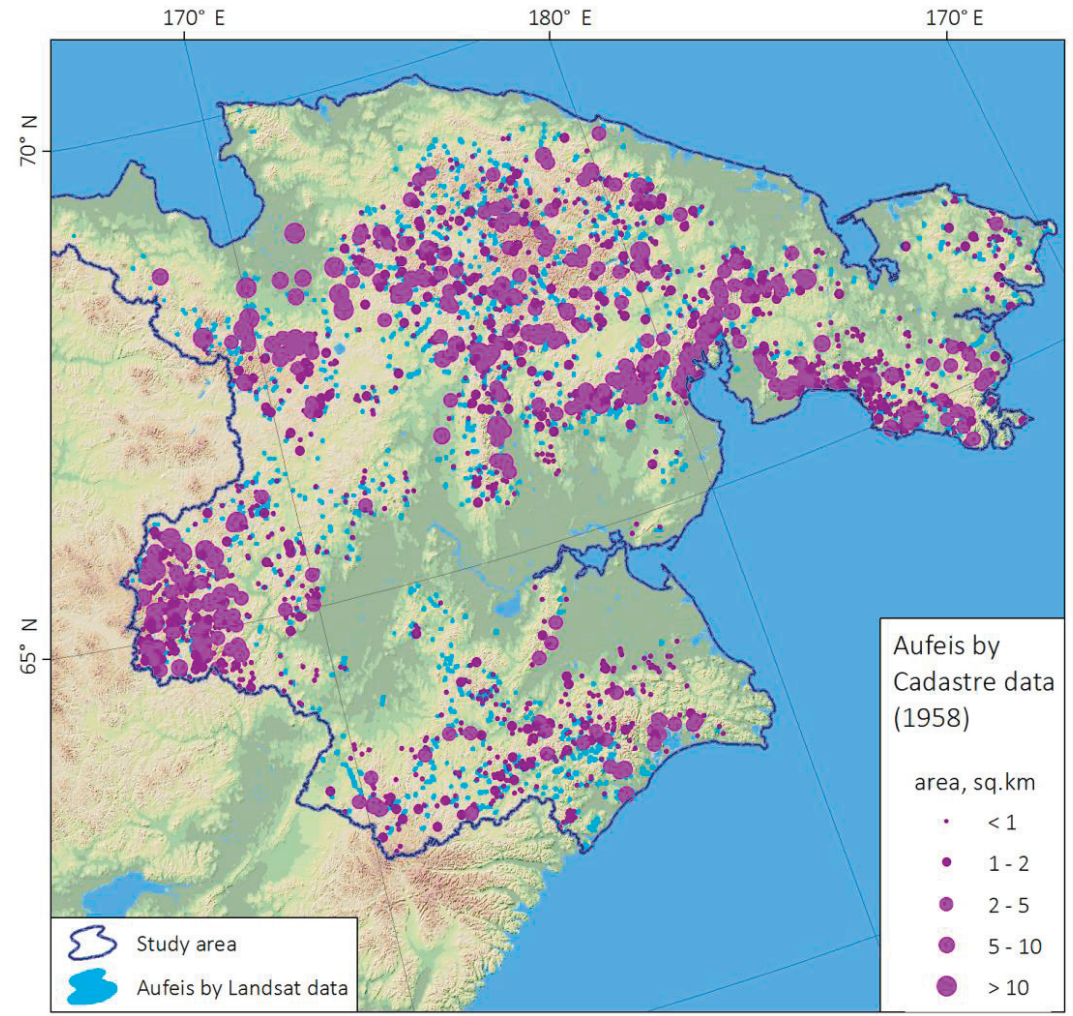

Elevation, $m$

$100 \quad 200 \quad 300 \quad 500 \quad 750 \quad 100015002000$ higher

$0 \quad 50100 \quad 200 \mathrm{~km}$

Fig. 2. Example of a Catalogue based on Cadastre data (1958) and Landsat images for the Chukotka area.

Second part of the Atlas is cartographic. It contains the maps of the distribution of aufeis fields in the main river basins (Fig. 3). Medium- and large-scale maps of reference aufeis fields reveal the seasonal and long-term dynamics of ice phenomena (Fig. 4), as well as the landscape conditions of aufeis formation. The analysis of patterns of aufeis location is supplemented by multi-scale maps of aufeis hazard and maps of aufeis resources. In conclusion, it is intended to highlight the experience and prospects of practical use of aufeis fields and aufeis landscapes.

At the end of the project the electronic version of the Atlas will be available on the Internet. The Atlas is designed wide scope of readers, including the scientists, students and people who love Nature. The Atlas will be useful in solving regional problems of management and environmental protection, when designing routes for linear engineering structures. 

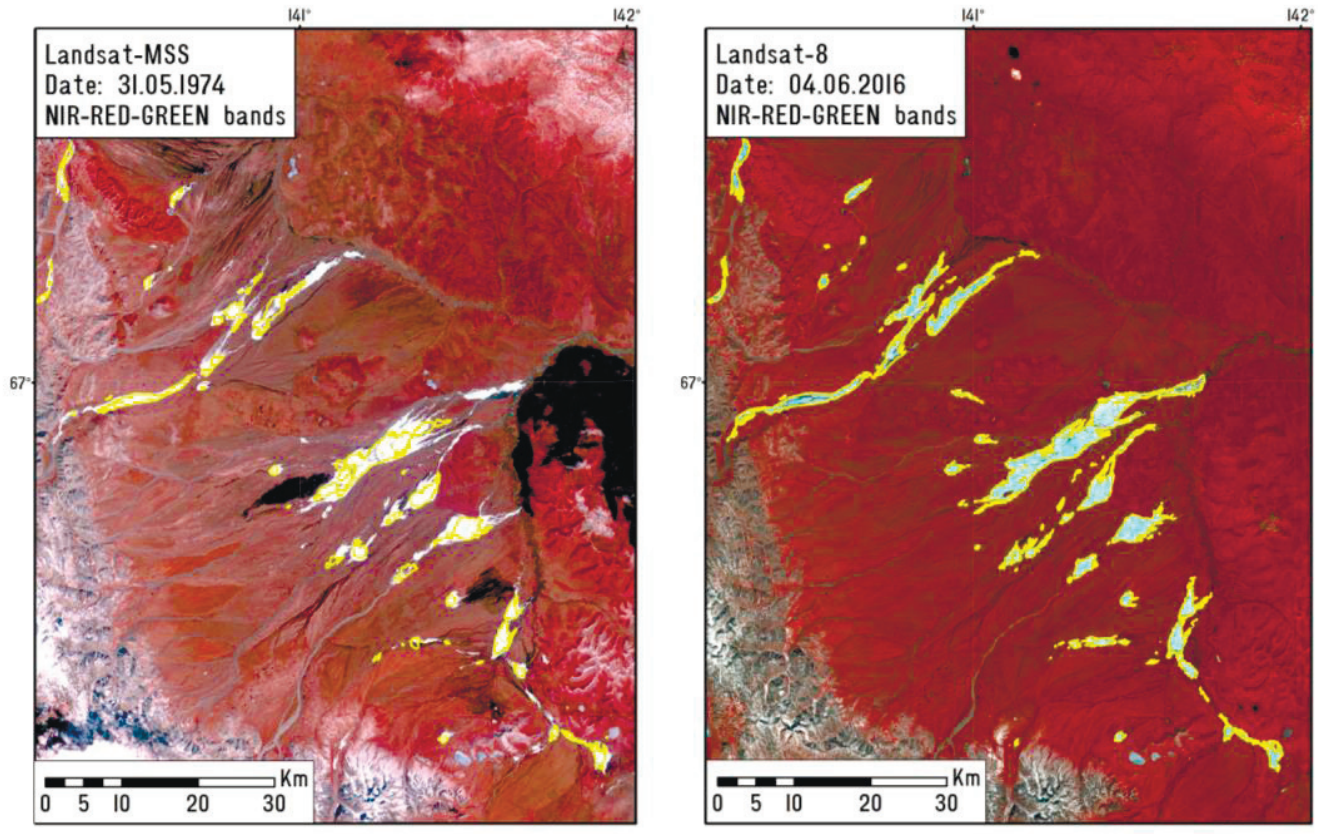

Fig. 3. Changes in the area of aufeis in the Syuryuktyakh river basin from 1947 to 2016.
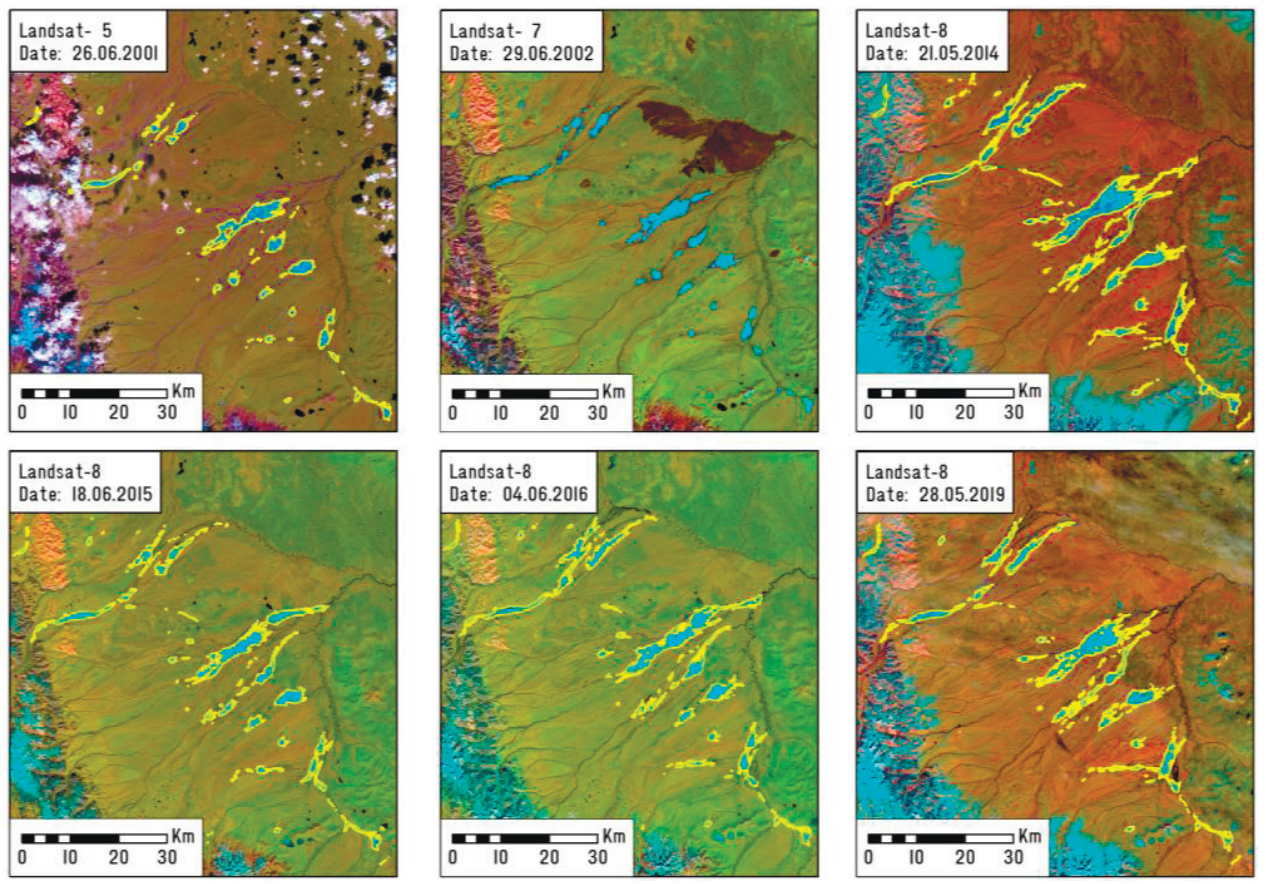

Fig. 4. Changes in the area of aufeis in the Syuryuktyakh river basin from 2001 to 2019.

The database was created with the support of the Russian Foundation for Basic Research (project \# 20-05-00666 A), and the Atlas was elaborated with the support of Russian Geographical Society (initiative grant "Atlas of giant aufeis-taryns of the North-East of Russia", 2019-2020). 


\section{References}

1. V. R. Alekseev, Ice and snow, 56 (1), 73-92 (2016)

2. T. Ensom, V.R. Alekseev, D.L. Kane, O.M. Makarieva, P. Marsh, P.D. Morse, Permafrost and Periglacial Processes (2020, accepted)

3. O. Makarieva, A. Shikhov, N. Nesterova, A. Ostashov, Earth Syst. Sci. Data, 11, 409420 (2019)

4. H. Crites, S.V. Kokelj, D. Lacelle, Sci Rep, 10, 3283(2020)

5. V. R. Alekseev, Naledi. (Nauka, Novosibirsk, 1987)

6. A. S. Simakov, Explanatory note to the Cadaster of the aufeis in the North-East of the USSR. (North-Eastern geological Department, Magadan, 1958)

7. Z. G. Shilnikovskaya, Cadastre of the aufeis in the North-East of the USSR, scale 1: 2000000, compiled by A. S. Simakov and Z. G. Shilnikovskaya (Central integrated expedition of the North-Eastern geological Department, Magadan, 1958)

8. O. M. Makarieva, A. N. Shikhov, A. A. Astashov, N. V. Nesterova, Ice and Snow, 59(2), 201-212 (2019)

9. V.R. Alekseyev, V.V. Gorin, S.V. Kotov, Ice and Snow, 4, 85-93 (2011)

10. O. Makarieva, A. Shikhov, A. Ostashov, N. Nesterova, Aufeis (naleds) of the NorthEast of Russia: GIS catalogue for the Indigirka River basin (PANGAEA, https://doi.org/10.1594/PANGAEA.891036, 2018) 